\title{
PEMODELAN MATEMATIKA TERHADAP KESTABILAN POPULASI MODEL LOTKA-VOLTERRA DENGAN BANTUAN MATLAB
}

\author{
Feronika Paska Purba ${ }^{[1]}$, Rodelta Nababan ${ }^{[2]}$, Ruth Margaretha Tambunan ${ }^{[3]}$ \\ Universitas Negeri Medan \\ Fakultas Matematika dan Ilmu Pengetahuan Alam \\ ${ }^{1}$ feronikapurba3010@gmail.com \\ 2 rodeltanababan17@gmail.com \\ 3 tambunanruth45@gmail.com
}

\begin{abstract}
ABSTRAK
Perkembangan IPTEK sekarang ini telah memberikan kemudahan berbagai penelitian. Salah satunya adalah perhitungan masalah sehari-hari dengan pembuktian teorema-teorema baru. Hal ini memungkinkan para peneliti juga untuk mengembangkan teorema matematika yang sudah lama tidak tuntas. Tujuan dari penelitian ini adalah membuat pemodelan dan simulasi matematika tentang Kestabilan populasi model lotka-volterra menggunakan alat bantu aplikasi Matlab R2010a. Pemodelan Matematika terkait model Predator-Prey atau Lotka-Volterra dapat dianalisis dengan perhitungan pada Matlab. Untuk mendefinisikan variable - variabel atau mengeksekusi program dalam MATLAB, maka dapat dilakukan pada ruang "Command Window", di mana ruang ini dapat ditutup, restore dan resize ruang window-nya. Kita dapat mengamati perubahan laju pertumbuhan kedua populasi untuk berbagai kondisi.
\end{abstract}

Kata Kunci : Pemodelan Matematika, Kestabilan, Model Lotka- Volterra, Matlab. 


\section{PENDAHULUAN}

Ada banyak di dunia ini yang sudah dipresentasikan menggunakan pemodelan matematika. Pemodelan matematika ini digunakan untuk mempresentasikan problem dunia nyata dalam pernyataan matematika agar didapat pemahaman yang lebih tepat dari permasaahan tersebut. Pemodelan matematika dimulai dengan pengalaman yang nyata dan kembali ke kehidupan nyata (suwanto, yunda, \& lili, 2017).

Pemodelan matematika diperlukan untuk menambah keefisienan gagasan dalam waktu singkat, dapat memprediksi kejadian yang akan muncul dalam sebuah fenomena atau perluasan nya,dan sebagainya (simanullang \& clara, 2008). Salah satu masalah nyata yang dapat di modelkan kedalam matematika adalah keseimbangan atau kestabilan populasi. Dimana kita tahu bahwa kestabilan populasi dapat dikaitkan dengan banyak nya mangsa dan pemangsa nya atau predator-prey. Apabila tidak stabil maka akan terjadi kepunahan baik itu pada pemangsa nya maupun mangsanya.

Perkembangan dan kehadiran teknologi komputer dewasa ini telah memberikan kemudahan berbagai penelitian. Salah satunya adalah perhitungan masalah sehari-hari dengan pembuktian teorema-teorema baru. Hal ini memungkinkan para peneliti juga untuk mengembangkan teorema matematika yang sudah lama tidak tuntas. Perhitungan manual yang hampir mustahil dilakukan menyebabkan suatu teorema tidak terbukti. Namun adanya Software memberikan kemajuan pesat pada bidang keilmuan Matematika, salah satunya Matlab (Matrix Laboratory).

Pada makalah ini akan dijelaskan tentang pemodelan matematika terhadap kestabilan populasi buaya dan ikan pada sebuah danau model lotka-volterra menggunakan matlab.disertai gambar-gambar yang dapat mempermudah pembaca dalam melihat perbandingan mangsa dan pemangsa sesuai kondisi awal yang diberikan. 


\section{BATASAN MASALAH}

Pada penelitian ini penulis membatasi pembahasan tentang pemodelan matematika sederhana, Persamaan Diferrensial Biasa Orde 1 dan array satu dimensi,

\section{TUJUAN PENULISAN}

Tujuan dari penelitian ini adalah membuat pemodelan dan simulasi matematika tentang Kestabilan populasi model lotka-volterra menggunakan alat bantu aplikasi Matlab R2010a .

\section{LANDASAN TEORI}

Pemodelan Matematika terkait Predator-Prey atau yang dikenal dengan Lotka-Volterra dapat dianalisis dengan perhitungan pada Matlab. Untuk mendefinisikan variable - variabel atau mengeksekusi program dalam MATLAB, maka dapat dilakukan pada ruang "Command Window", di mana ruang ini dapat ditutup, restore dan resize ruang window-nya. M file dapat dipanggil ke ruang Command Window secara otomatis, bila file tersebut terdapat dalam file explorer window. MATLAB memiliki tiga jenis jendela:

\begin{tabular}{|l|l|}
\hline Jendela & Fungsi \\
\hline Command window & Mengetikkan perintah \\
\hline Graphics window & Menampilkan grafik \\
\hline Jendela edit (edit window) & $\begin{array}{l}\text { Menciptakan dan } \\
\text { memodifikasi M-file }\end{array}$ \\
\hline
\end{tabular}

Pada bagian ini akan dibahas model matematika yang menjelaskan antara interaksi spesies rantai makanan. Adapun model Lotka-Voltera ini adalah model antara predator dan mangsa pada sebuah lingkungan pada danau yang bekerjasama satu sama lain. Misalkan X memberikan menjadi predator dan $\mathrm{Y}$ buat mangsa pada saat t. Bila predator dan mangsa tidak saling berinteraksi, maka model pertumbuhan populasi mangsa ialah 


$$
\frac{d X}{d t}=r X(t)
$$

Pada hal ini $r$ menunjukkan laju kelahiran yang berasal dari populasi si mangsa dimana bila populasi mangsa berkurang,maka populasi dari predator juga akan berkurang. Dimana mangsa itu merupakan makanan berasal si predator. Sebagai akibatnya laju pertumbuhan populasi dari predator ialah

$$
\frac{d Y}{d t}=-k Y(t)
$$

Dimana pada hal ini k memberikan laju kematian asal populasi predator.karena populasi berasal predator itu bergantung di populasi dari simangsa serta akan mengakibatkan jumlahnya berkurang. Apabila kedua spesies ini saling berinteraksi dimana populasi dari si predator bergantung di populasi dari mangsa sebagai makanan,maka contoh Lotka-Volterra nya ialah menjadi berikut:

$$
\begin{gathered}
\frac{d X}{d t}=r(t)-a X(t) Y(t) \\
\frac{d W}{d t}=-k Y(t)+b X(t) W(t)
\end{gathered}
$$

Dimana k,r,a,b itu menunjukkan interkasi antara kedua spesies yang tidak sama dimana k nya itu memberikan laju kelahiran dari mangsa,a memberikan hubungan antara mangsa serta predator yg berpengaruh terhadap mangsa yang menyebabkan berkurangnya mangsa,k membagikan laju kematian asal populasi predator,serta b membagikan tingkat interraksi antaramangsa serta predator yg berpengaruh terhadap predator.

\section{METODE PENELITIAN}

Penelitian ini menggunakan logika algoritma matematika yang diimplementasikan menggunakan pemrograman Matlab. 


\section{HASIL DAN PEMBAHASAN}

\section{- Lotka_Volterra}

Pada bagian ini akan dibahas contoh kasus tentang penyeleasaian suatu masalah pada model Lotka -Volterra. Di sebuah danau terdapat dua jenis spesies,yaitu buaya dan ikan

Notasikan :

$\mathrm{B}=$ banyaknya populasi buaya

I=banyaknya populasi ikan

Dimana jika tidak adanya interaksi

$\frac{d I}{d t}=r I \quad \rightarrow$ r konstanta positif

$\frac{d B}{d t}=-k B \quad \rightarrow: \mathrm{k}$ konstanta positif

Pada kondisi nyata buaya itu sebagai predator dan ikan itu sebagai mangsa.Asumsikan bahwa makanan ikan itu sangat berlimpah sedangkan makanan dari buaya itu tergantung dari populasi ikan. Maka laju pertumbuhan buaya bergantung pada pertubuhan ikan.

Dengan menggunakan model Lotka-Volterra

$$
\begin{aligned}
& \frac{d I}{d t}=t I-a B I \\
& \frac{d B}{d t}=-k B+b B I
\end{aligned}
$$

dimana k,r,a,bitu adalah konstanta positif,factor BI itu berperan sebagai laju pertumbuhan dari buaya dan ikan. Untuk $\mathrm{I}<<$ dan $B<<\operatorname{maka} \frac{d I}{d t}>0$ dan $\frac{d B}{d t}<0 \quad \rightarrow$ jika jumlah ikan dan buaya sama-sama sedikit 
Untuk mengetahui interaksi antara buaya dan ikan dapat digambarkan pada bidang fasa (phrase plane). Untuk konstanta $\mathrm{r}=0,08, \mathrm{a}=0,001, \mathrm{k}=1$ dan $\mathrm{b}=0,00002$

Laju pertumbuhan ikan

$$
\frac{d I}{d t}=0,08 B-0,001 B I
$$

Laju pertumbuhan buaya

$$
\begin{gathered}
\frac{d I}{d t}=-B+0,00002 B I \\
\Rightarrow \frac{d B}{d I}=\frac{\frac{d B}{d t}}{\frac{d I}{d t}}=\frac{-B+0,00002 B I}{0,08-0,001 B I}
\end{gathered}
$$

Medan arah (isolin) dari $\frac{d B}{d I}$

Solusi kondisi awal $\mathrm{I}(0)=30$ dan $\mathrm{B}(0)=1$

Orientasi ditentukan dari anak panah isoklin atau dari $\frac{\frac{d I}{d t}(0)}{\frac{d B}{d t}(0)}$

$$
\frac{d I}{d t}=0,08(1)-0,001(1)(30)=0,05
$$

Kurva solusi $\mathrm{I}(\mathrm{t})$ dan $\mathrm{B}(\mathrm{t})$ merupakan fungsi periode.

- Matlab

Pertama, Membuka M-File dengan mengklik new script pada file lalu klik New dan pilih Script atau dengan menekan tombol Ctrl+N secara bersamaan kemudian mengetikkan script sebagai berikut.

\%kesetimbangan populasi 


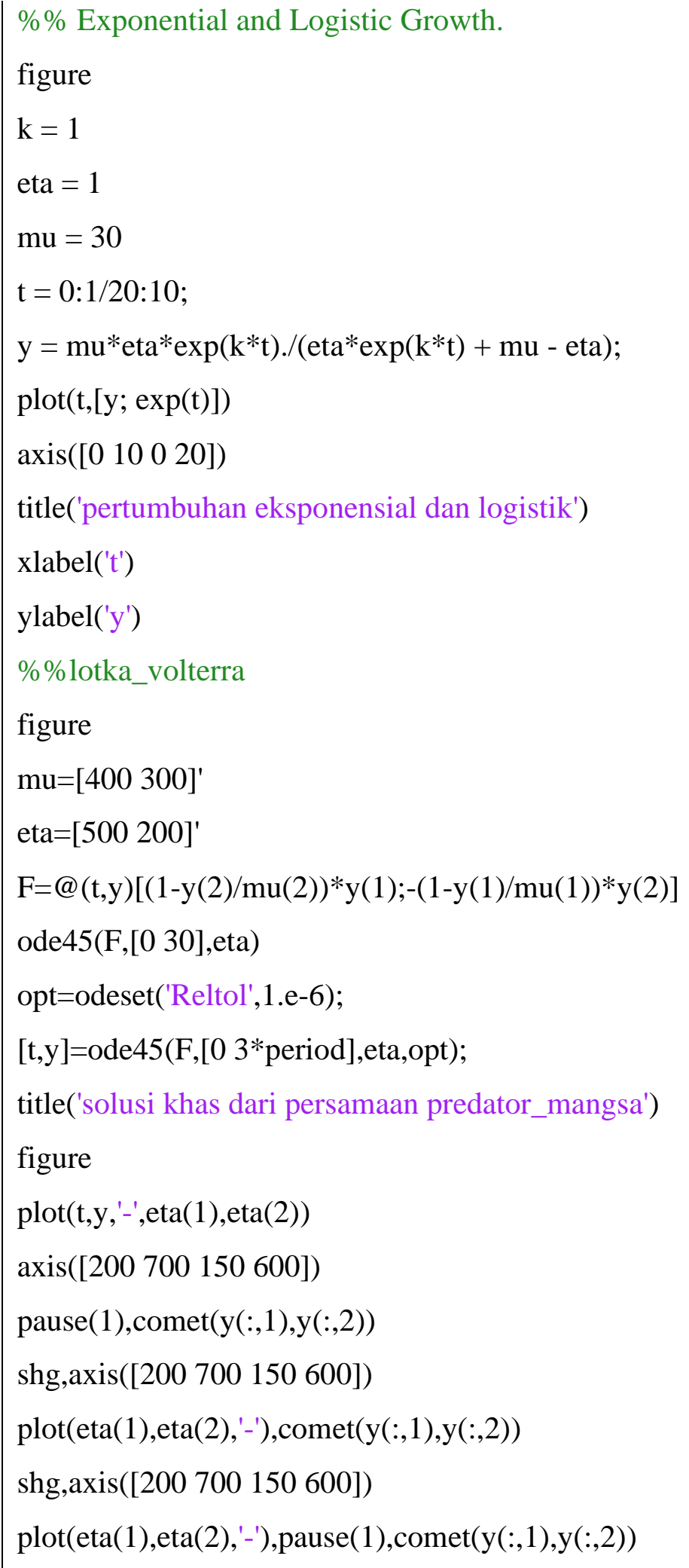


title('titik-titik predator mangsa')

figure

$\mathrm{mu}=\left[\begin{array}{lll}400 & 300\end{array}\right]^{\prime}$

eta $=\left[\begin{array}{lll}500 & 200]^{\prime}\end{array}\right.$

$\mathrm{F}=@(\mathrm{t}, \mathrm{y})[(1-\mathrm{y}(2) / \mathrm{mu}(2)) * \mathrm{y}(1) ;-(1-\mathrm{y}(1) / \mathrm{mu}(1)) * \mathrm{y}(2)]$

ode45(F,[0 25],eta)

period $=6.5357$

$[\mathrm{t}, \mathrm{y}]=\operatorname{ode} 45(\mathrm{~F},[0,3 *$ period $], \mathrm{eta})$;

$\operatorname{plot}(\mathrm{t}, \mathrm{y})$

title('model lotka-volterra')

Kemudian save file, lalu run-kan dengan menekan tombol f5, maka grafik akan ditampilkan pada Figure.jika ingin mengubah nilai-nilai dari variabel dapat mengubah program atau mengetikkan nya di command.

\section{- Kestabilan Populasi Pada Bidang Koordinat}

Dalam KBBI kestabian dapat diartikan dengan kukuh ,tidak goyah atau seimbang.menurut sugiyono populasi adalah wilayah generalisasi yang terdiri dari objek dan subjek.populasi dalam artikel ini adalah buaya-ikan dalam sebuah danau.

Kita dapat mengamati perubahan laju pertumbuhan kedua populasi untuk berbagai kondisi nilai B(buaya) dan I(ikan) lainnya. Untuk lebih memahami interaksi antara dua spesises ini, dinamika perubahan populasi akan digambarkan pada bidang fasa (phase plane) sumbu horizontal menyatakan jumlah populasi ikan sedangkan sumbu vertical menyatakan jumlah populasi buaya .

Pada bagian ini akan dipaparkan mengenai penjelasan dari grafik atau figure yang dihasilkan dari script yang sudah kami paparkan diatas. Gambar 1 menunjukkan dua solusi 
ketika dan $\mathrm{k}=1$. Fungsi eksponensial $\mathrm{y}(\mathrm{t})=$ et memberikan kurva hijau yang berkembang pesat. Dengan daya dukung $=30$, fungsi logistic memberikan kurva biru yang tumbuh lebih lambat. Kedua kurva memiliki nilai awal dan kemiringan awal yang sama. Fungsi eksponensial tumbuh secara eksponensial, sedangkan fungsi logistik mendekati, tetapi tidak pernah melebihi, daya dukungnya.

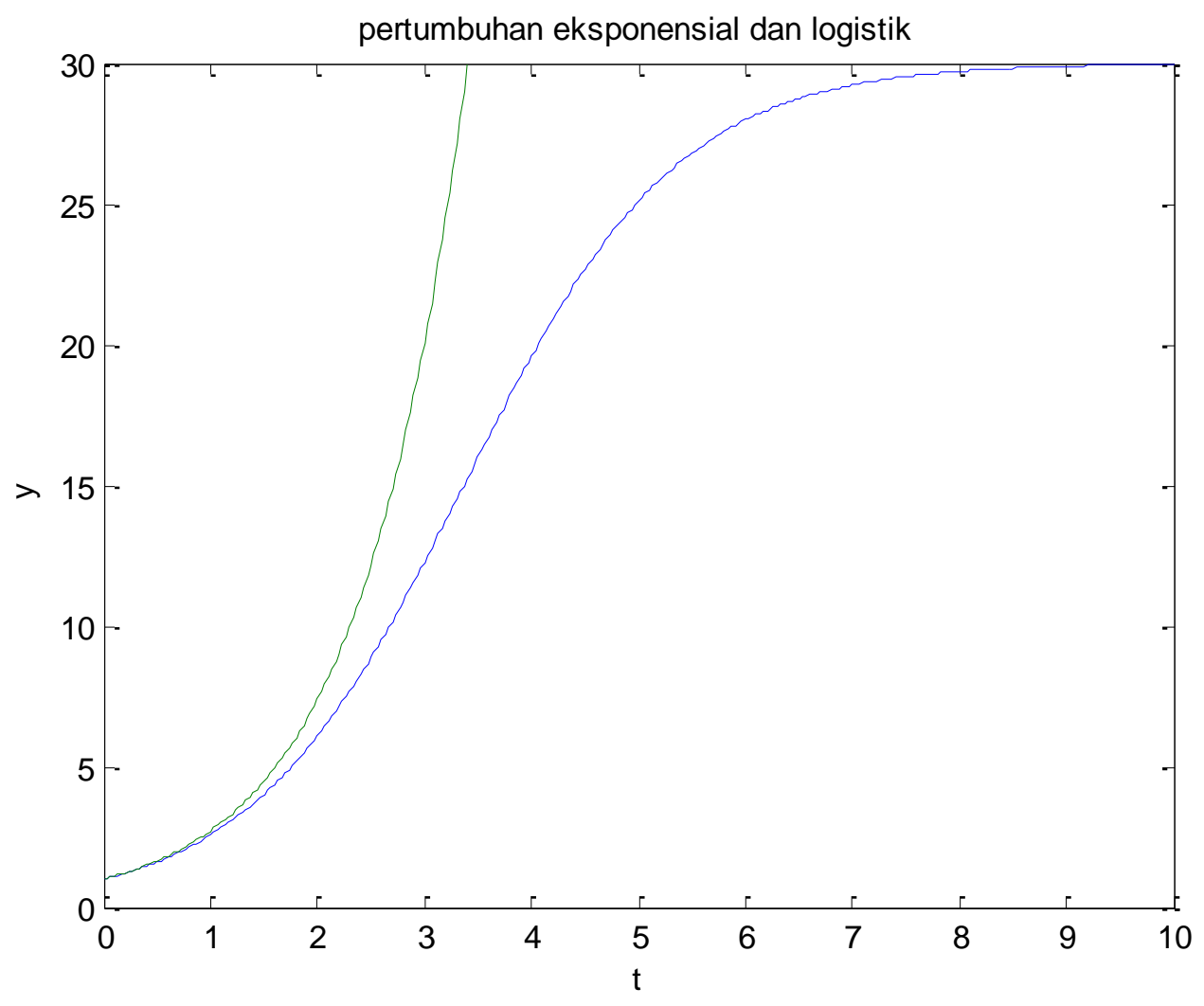

Gambar 1. pertumbuhan eksponensial dan logistik

Didapat dengan script sebagai berikut:

$$
\begin{aligned}
& \text { figure } \\
& \mathrm{k}=1 \\
& \text { eta }=1 \\
& \mathrm{mu}=30
\end{aligned}
$$




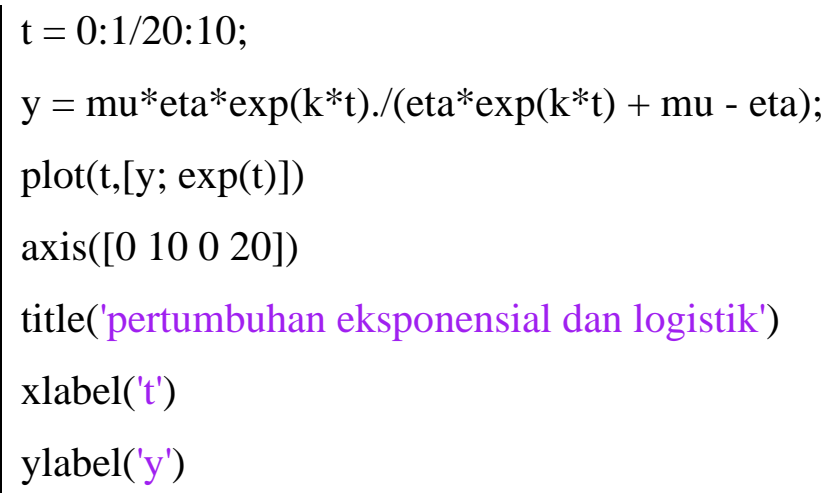

Dengan demikian kita dapat menggambarkan kurva solusi dari buaya dan ikan masing masing terhadap waktu. Solusi dari masing-masing populasi terhadap waktu dapat digambarkan sebagai berikut.

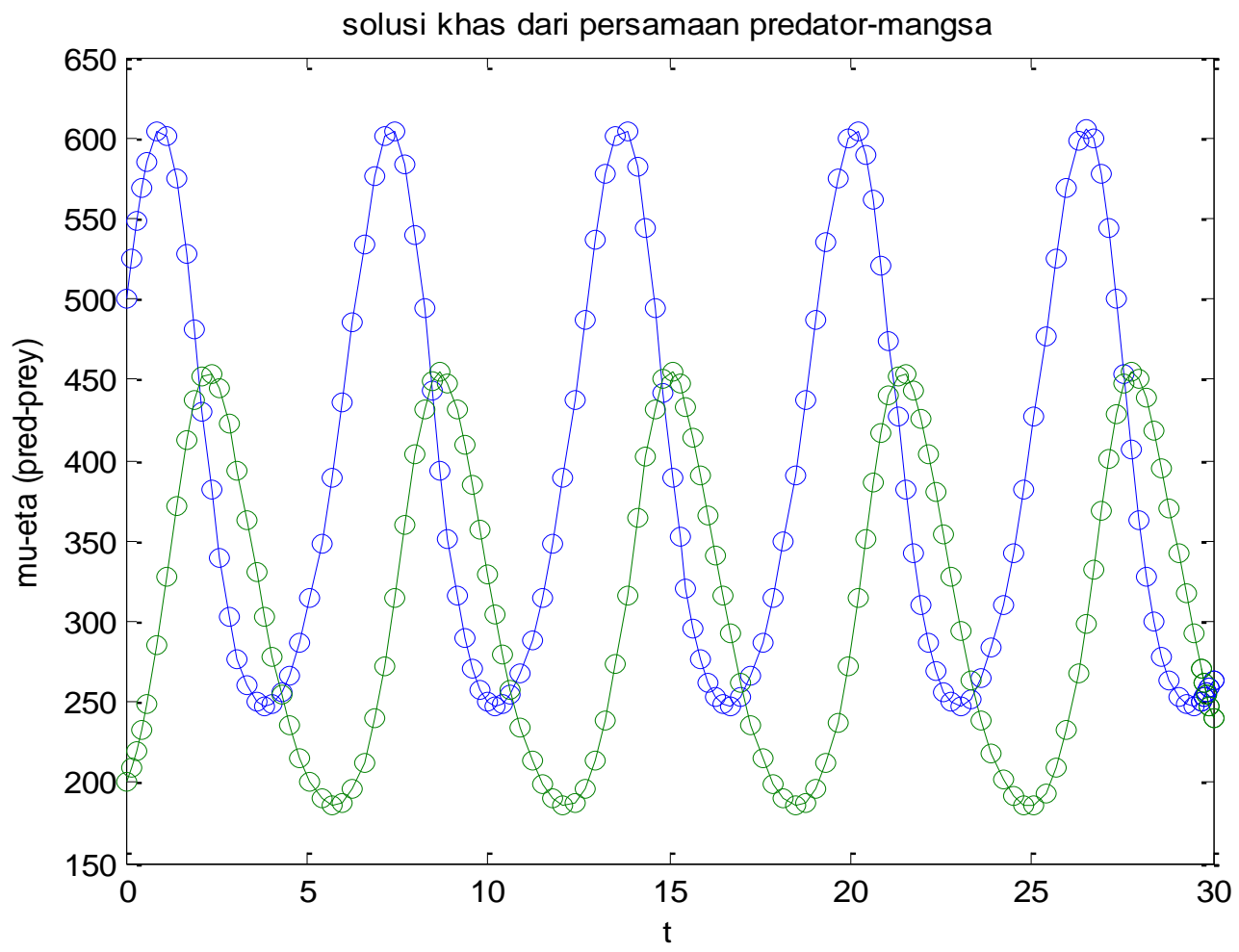

Kurva sebelah kiri untuk ikan dan kurva sebelah kanan untuk buaya. Titik ekstrim lokal yaitu titik maksimum lokal ataupun minimum lokal dari ikan maupun untuk buaya dapat kita peroleh dari gambar bidang fasa sebelumnya. Jika kita perhatikan disini nilai maksimum 
dari ikan sekitar 600 sekian sedangkan titik kecilnya diperkirakan 200 sekian, dan ini bergerak secara periodik. Hal yang sama kita gambarkan untuk buaya. Disini skala penggambarannya berbeda tergantung rentang populasi masing-masing. Script nya sebagai berikut:

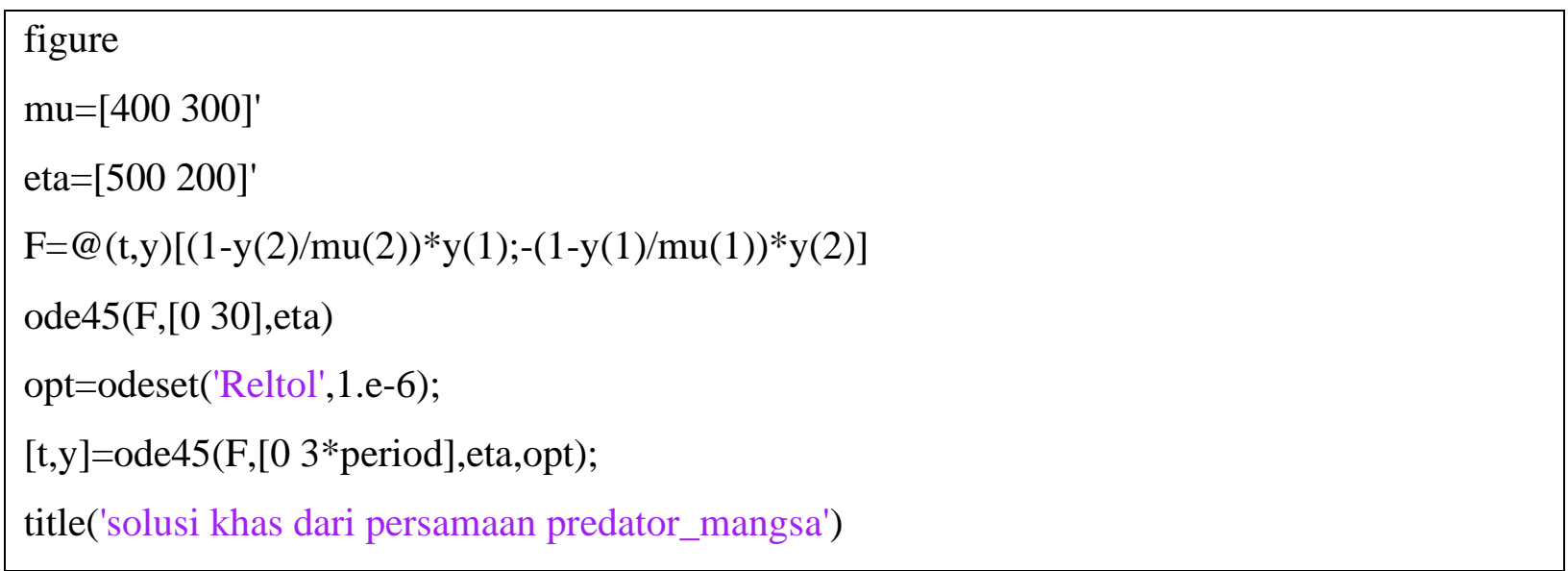

Berikut gambar drag either dot dari predator_prey

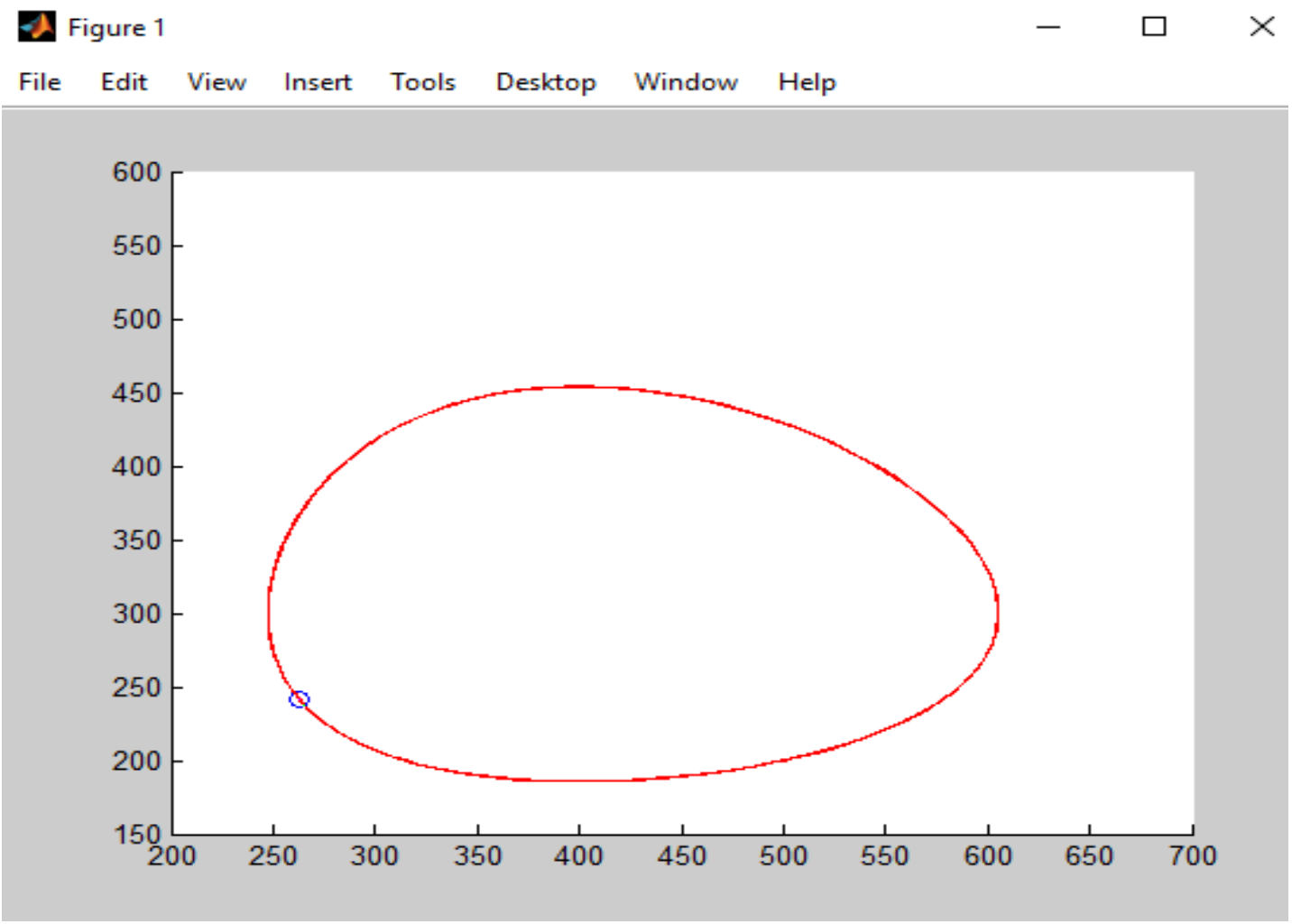


Kurva yang berwarna merah ini pada bidang fasa menggambarkan dinamika perubahan populasi buaya dan ikan terhadap waktu. Dalam hal kurva (warna biru pada gambar) bergerak ke kanan artinya jumlah Ikan akan bertambahsedangkakn bila kurvanya bergerak ke kiri menunjukkan jumlah ikan berkurang. Bila kurva bergerak ke atas berarti jumlah buaya bertambah sedangkan bila bergerak ke bawah ini menunjukkan jumlah buaya berkurang.Untuk melihat pergerakan nya dapat digunakan program yang sudah dilampirkan diatas pada bagian matlab. jika langsung mempraktekkan pada matlab akan ditunjukkan beberapa gambar karena pada makalah ini hanya ditunjukkan 1 gambar saja dan pergerakan nya tidak terlihat. Script nya adalah sebagai berikut :

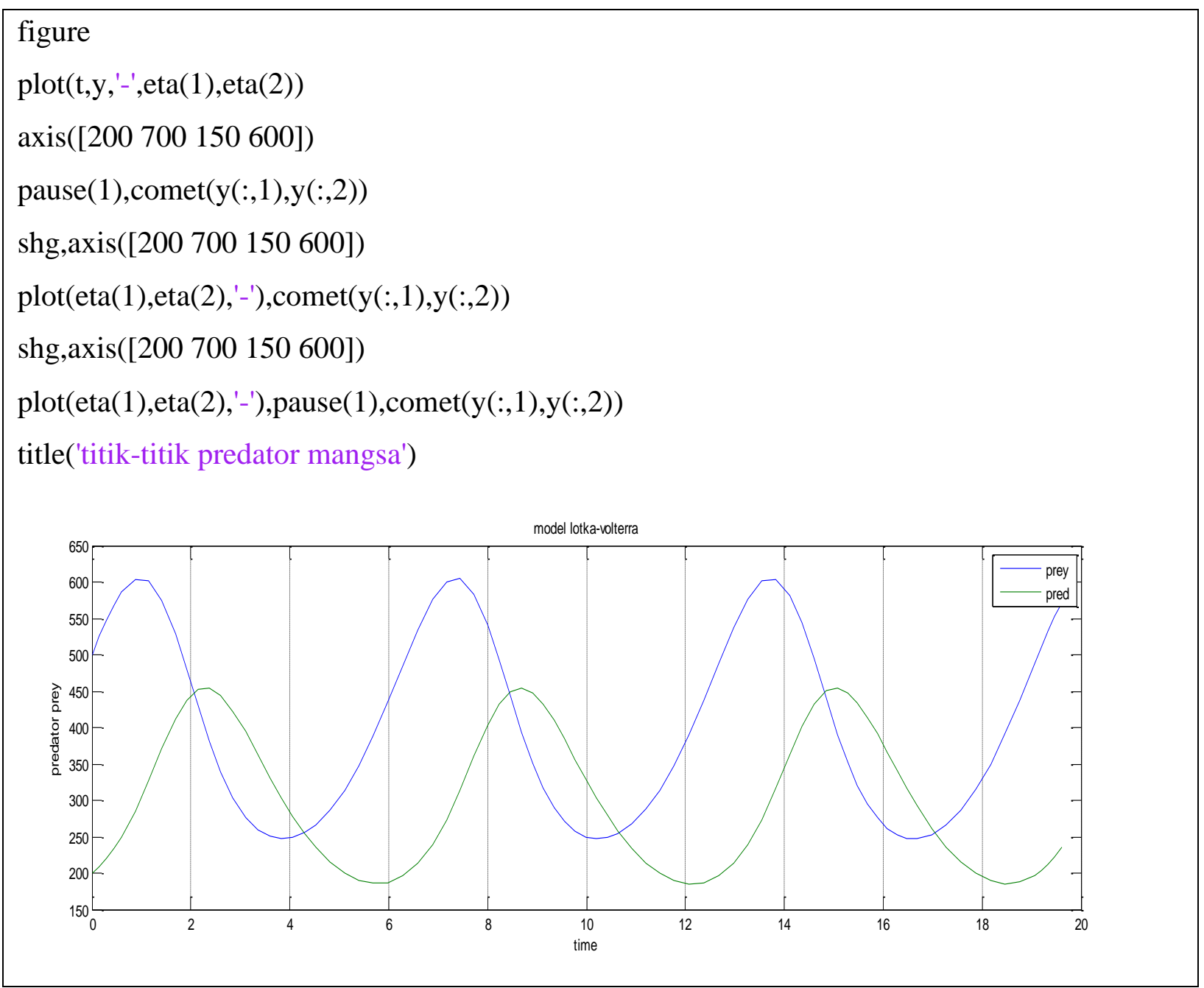


Interaksi antara kedua populasi ini dapat kita gambarkan dalam satu koordinat yang sama tentunya dengan skala yang berbeda. Melalui kurva ini kita lihat populasi ikan mencapai maksimum terlebih dahulu daripada buaya. Setelah itu ikan akan berkurang sedangkankan buaya masih naik. Suatu saat buaya mencapai maksimum dan populasinya menurun demikian juga ikan menurun. Kemudian akan naik lagi buaya menurun. ikan naik lagi dan buaya juga menaik. Peristiwa ini akan berulang secara periodic. Scriptnya adalah sebagai berikut :

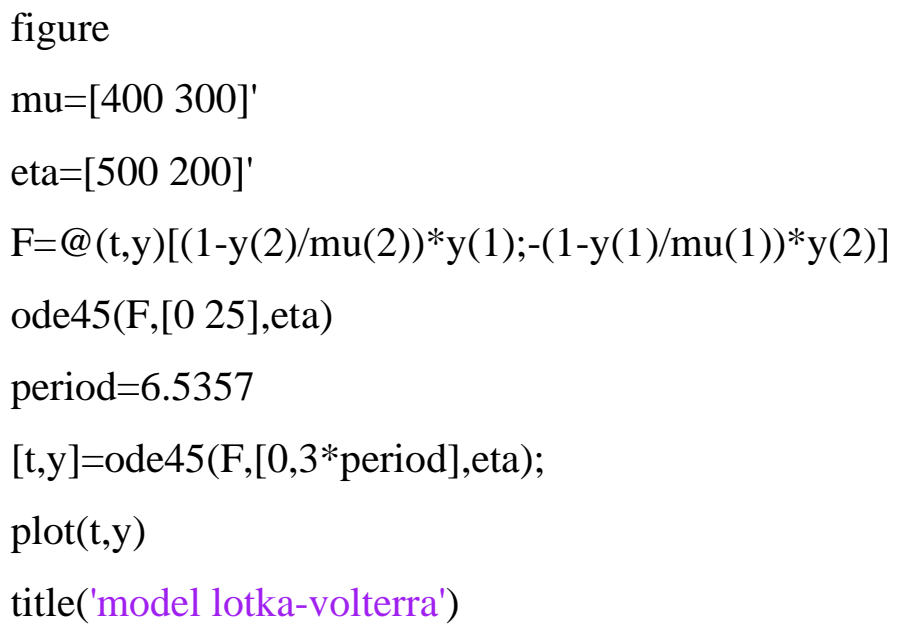

Pengamatan dinamika populasi buaya dan ikan ini akan sangat sukar dilakukan secara manual karena kita harus menggambar medan arah dari dB dI. Jika hal ini dilakukan secara manual tentunya sangat sulit dalam melakukan perhitungannnya.namun untuk mendapatkan hasil maksimal perlu dipahami pengerjaan nya secara manual,melatih nya dengan menggunakan persoalan sederhana.

\section{KESIMPULAN}

Pengamatan dinamika kestabilan populasi buaya dan ikan pada sebuah danau model lotka-volterra ini akan sangat sukar dilakukan secara manual. Maka pengamatan dan Pemodelan Matematika terkait model Predator-Prey atau yang dikenal dengan Lotka-Volterra dapat dianalisis dengan perhitungan pada Matlab agar mempermudah perhitungan dan 
membuat gambar nya untuk diamati. Terdapat script pada masing-masing gambar untuk mempermudah pembaca dapat langsung mencobanya pada software matlab masing-masing.

\section{DAFTAR PUSTAKA}

Boyce, W. E. \& Diprima, R. C. 2001. Elementary Differential Equations and Boundary Value Problems, Seventh Edition. John Wiley and Sons, Inc., New york.

Moler,cleve.2011. Numerycal computing with matlab.society for industrial and applied matheatics: saltlake.

Chauvet, E., Paullet, J. E., Previte, J. P. \& Walls, Z. 2002. A Lotka-Volterra Three-Spescies Food Chain. Mathematics Magazine, $75: 243$ - 255.

Howard, A. 1987. Aljabar Linear Elementer, Edisi kelima. Terj. dari Elementary Linear Algebra, Fifth Edition, oleh Pantur Silaban \& I Nyoman. Erlangga:Jakarta.

Monica, r., leli, d., \& rolan, p. (2014). Kestabilan populasi model- lotka volterra tiga spesies dengan titik kesetimbangan. JOM MIPA.

Siahaan, V. 2020. Buku Resep Pemograman Matlab. SPARTA : Balige.

Simanullang, B., \& clara, i. s. (2008). Pemodelan Matematika. Academia edu.

Stewart, J. 2011. Kalkulus, Edisi kelima: Jilid 2. Terj. dari Calculus, Fifth Edition, oleh Sungkono C. Salemba Teknik, Jakarta.

Suwanto, f. r., yunda, v. t., \& lili, r. (2017). Kemampuan abstraksi dalam pemodelan matematika. 301-306. 